\title{
A potential therapeutic effect of CYP2C8 overexpression on anti-TNF- $\alpha$ activity
}

\author{
WANJUN LIU, BEI WANG, HU DING, DAO WEN WANG and HESONG ZENG \\ The Institute of Hypertension and Department of Internal Medicine, Tongji Hospital, Tongji Medical College, \\ Huazhong University of Science and Technology, Wuhan, Hubei 430030, P.R. China
}

Received February 20, 2014; Accepted July 1, 2014

DOI: $10.3892 /$ ijmm.2014.1844

\begin{abstract}
Epoxyeicosatrienoic acids (EETs) are generated from arachidonic acid catalysed by cytochrome P450 (CYP) epoxygenases. In addition to regulating vascular tone EETs may alleviate inflammation and ROS. The present study was conducted to determine whether $C Y P 2 C 8$ gene overexpression was able to increase the level of EETs, and subsequently prevent TNF- $\alpha$ induced inflammation and reactive oxygen species (ROS) in human umbilical vein endothelial cells (HUVECs) and macrophages. Peroxisome proliferator-activated receptor $\gamma($ PPAR $\gamma)$ activation, nuclear factor $-\kappa \mathrm{B}(\mathrm{NF}-\kappa \mathrm{B})$ activation, endothelial nitric oxide synthase (eNOS) activation, gp-91 activation, and inflammatory cytokine expression were detected by western blot analysis or enzyme-linked immunosorbent assay. Intracellular reactive oxygen species (ROS) was measured by flow cytometry, while the migration of vascular smooth muscle cells (VSMCs) was detected by Transwell assay. pCMV-mediated CYP2C8 overexpression and its metabolites, EETs, markedly suppressed TNF- $\alpha$ induced inflammatory cytokines IL-6 and MCP-1 expression via the activation of $\mathrm{NF}-\kappa \mathrm{B}$ and degradation of I $\kappa \mathrm{B} \alpha$. Moreover, pretreatment with 11,12-EET significantly blocked TNF- $\alpha$-induced ROS production. CYP2C8-derived EETs also effectively alleviated the migration of VSMCs and improved the function of endothelial cells through the upregulation of eNOS, which was significantly decreased under the stimulation of TNF- $\alpha$.
\end{abstract}

Correspondence to: Dr Hesong Zeng, The Institute of Hypertension and Department of Internal Medicine, Tongji Hospital, Tongji Medical College, Huazhong University of Science and Technology, 1095 Jiefang Avenue, Wuhan, Hubei 430030, P.R. China E-mail: zenghs@tjh.tjmu.edu.cn

Abbreviations: CYP2C8, cytochrome P450 enzymes 2C8; EET, epoxyeicosatrienoic acid; ROS, reactive oxygen species; HUVEC, human umbilical vein endothelial cell; VSMC, vascular smooth muscle cell; NF- $\kappa \mathrm{B}$, nuclear factor $\kappa \mathrm{B}$; I $\mathrm{I} \mathrm{B} \alpha$, inhibitor of $\mathrm{NF}-\kappa \mathrm{B} \alpha$; IL, interleukin; MCP-1, monocyte chemotactic protein-1; PPAR $\gamma$, peroxisome proliferator-activated receptor $\gamma ; \mathrm{C} 26$, compound 26

Key words: CYP2C8, epoxyeicosatrienoic acids, inflammation, reactive oxygen species, nuclear factor- $\kappa \mathrm{B}$, atherosclerosis
Furthermore, these protective effects observed were mediated by PPAR $\gamma$ activation. To the best of our knowledge, the results of the present study demonstrated for the first time that CYP2C8-derived EETs exerted antivascular inflammatory and anti-oxidative effects, at least in part, through the activation of PPAR $\gamma$. Thus, the $C Y P 2 C 8$ gene may be useful in the prevention and treatment of vascular inflammatory diseases.

\section{Introduction}

Atherosclerosis is a complex pathological process that possesses many features of chronic inflammation (1) and oxidative stress in the vascular wall. It also plays a major role in atherogenesis. Reactive oxygen species (ROS), generated as byproducts of cellular metabolism, elicit numerous effects on cell functions in several cell types such as endothelial cells, macrophages and vascular smooth muscle cells (VSMCs) (2).

In endothelial cells, ROS regulate numerous signaling pathways including those regulating cell growth, proliferation, vaso-relaxation, inflammatory responses, barrier function and vascular remodeling (3). The vascular ROS production by NADPH oxidase or mitochondria is markedly enhanced in atherosclerotic arteries, which in turn limits the activity of nitric oxide (NO), thereby producing endothelial dysfunction (4). A number of in vitro and in vivo studies have demonstrated a critical role for ROS or enzyme systems involved in ROS production, including endothelial NO synthases, xanthine oxidase, enzymes of the respiratory chain, cytochrome $\mathrm{P} 450$ monooxygenases and NAD $(\mathrm{P}) \mathrm{H}$ oxidase in the vasculature (5). Upregulation of the $\mathrm{NAD}(\mathrm{P}) \mathrm{H}$ oxidase subunits gp91phox and Nox4 increases intracellular oxidative stress in macrophages and non-phagocytic vascular cells of human coronary atherosclerosis, respectively (6). Furthermore, the endothelial cell responds to various proinflammatory mediators such as oxLDL. oxLDL has been previously shown to upregulate the expression of MCP-1 via activation of ROS and nuclear factor (NF)- $\kappa B$ (7).

In macrophages, a recent study showed that the CD14/TLR4 (a Toll-like receptor 4)/MD-2 complex interacts with mmLDL, inducing cytoskeletal rearrangements and the secretion of macrophage inflammatory protein-2, MCP-1, tumor necrosis factor- $\alpha$ (TNF- $\alpha)$ and interleukin- $6(8,9)$ via ROS generation from spleen tyrosine kinase/Nox2 signaling (10). In addition, $\mathrm{NF}-\kappa \mathrm{B}$, the most well-known redox-dependent transcriptional 
factors, regulates a number of genes involved in inflammatory responses in macrophages (11).

In VSMCs, ROS mediates various functions including growth, migration, matrix regulation, inflammation and contraction (12) which are critical factors in the progression and complications of atherosclerosis. In addition, in VSMCs, ROS also mediate inflammation, e.g., MCP-1 expression via TNF- $\alpha$ (13).

The cytokine TNF- $\alpha$, characterized as a potent proinflammatory cytokine, induces oxidative stress in cells and increases intracellular ROS generation $(14,15)$. It also leads to the activation of $\mathrm{NF}-\kappa \mathrm{B}$. However, antioxidants have been shown to scavenge intracellular ROS production and block the NF- $\kappa \mathrm{B}$ activation (16). These results suggest that the suppression of ROS-dependent intracellular signaling may be an effective strategy for inflammatory vascular diseases.

Epoxyeicosatrienoic acids (EETs) are synthesized predominantly by the epoxygenases of the CYP2 family, including the 2C and 2J classes. CYP2C and CYP2J are mainly expressed in epithelial, endothelial, and smooth muscle cells, as well as cardiomyocytes, autonomic ganglion cells, and islet cells in the heart, vessel, kidney, lung and pancreas (17-20). Specifically, CYP2C8 is expressed mainly in the endothelium. EETs possess a number of biological effects in the cardiovascular and renal systems, including anti-inflammatory (17) and angiogenic (21) effects on endothelial cells, and inhibition of vascular smooth muscle cell migration (22). EETs have recently been reported to attenuate ROS (23). However, how CYP2C8-derived EETs affect ROS signaling pathways that lead to inflammation and atherosclerosis remains to be determined. The focus of the present study was CYP2C8 and its capacity to elucidate how the arachidonic acid metabolites, EETs, attenuate TNF- $\alpha$ induced inflammation through ROS in vascular endothelial cells and macrophages and improve endothelial function and provide new insight into how CYP2C8-derived EETs ameliorate vascular inflammatory diseases such as atherosclerosis.

\section{Materials and methods}

Materials. Chemicals and reagents were obtained as follows: Dulbecco's modified Eagle's medium (DMEM) and fetal bovine serum (FBS) were purchased from HyClone Laboratories, Inc. (Logan, UT, USA); HUVECs, VSMCs, macrophages cell lines and 2',7'-dichlorodihydrofluorescein diacetate $\left(\mathrm{HB}_{2 \mathrm{~B}} \mathrm{DCF}-\mathrm{DA}\right)$ were purchased from Wuhan Boster Biological Technology, Ltd. (Wuhan, China); exogenous EETs and PPAR $\gamma$-specific inhibitor GW9662 were from Cayman Chemical (Ann Arbor, MI, USA); RPMI-1640 medium and recombinant human TNF- $\alpha$ were from Sigma Chemical, Co. (St. Louis, MO, USA); pCMV-CYP2C8 plasmids from OriGene Technologies, Inc. (Rockville, MD, USA) were introduced into cells using Lipofectamine 2000 (Invitrogen, Carlsbad, CA, USA); antibodies against PPAR $\gamma$, lamin $\mathrm{B} 1$ and nuclear factor $\kappa \mathrm{B}(\mathrm{NF}-\kappa \mathrm{B})$ were from Santa Cruz Biotechnology, Inc. (Santa Cruz, CA, USA); antibodies against gp-91, CYP2C8 and eNOS were from Cell Signaling Technology (Beverly, MA, USA); antibody against $\beta$-actin was from Neomarkers (Fremont, CA, USA). All other reagents were purchased from standard commercial suppliers.
Cell culture. Human umbilical vein endothelial cells (HUVECs) were maintained in RPMI-1640 medium supplemented with $10 \% \mathrm{FBS}, 100 \mathrm{U} / \mathrm{ml}$ penicillin and $100 \mu \mathrm{g} / \mathrm{ml}$ streptomycin at $37^{\circ} \mathrm{C}$ under $5 \% \mathrm{CO}_{2}$. Macrophages and VSMCs were maintained in DMEM supplemented with $10 \%$ FBS, $100 \mathrm{U} / \mathrm{ml}$ penicillin and $100 \mu \mathrm{g} / \mathrm{ml}$ streptomycin at $37^{\circ} \mathrm{C}$ under $5 \% \mathrm{CO}_{2}$. HUVECs and macrophages were seeded in a 6 -well plate at a density of $3 \times 10^{5}$ cells/well. After the cells reached $60 \%$ confluence and the medium was removed, the cells were transferred to serumfree medium. The HUVECs and macrophages were pretreated with exogenous EETs $(1 \mu \mathrm{M})$ or transfected with CYP2C8 in advance for $30 \mathrm{~min}$ in the presence or absence of the specific PPAR $\gamma$ antagonist GW9662 $(1 \mu \mathrm{M})$, and subsequently stimulated with TNF- $\alpha(10 \mathrm{ng} / \mathrm{ml})$ for the indicated times.

Cell transfection and expression. The plasmids pCMV-CYP2C8 and pCMV-GFP were obtained from OriGene Technologies Inc. (Rockville). As the density of the cultured cells reached $\sim 50-70 \%$, each group was pretreated with Lipofectamine 2000 and then interfered by adding the pCMV-CYP2C8 and pCMV-GFP plasmids, respectively. After $6 \mathrm{~h}$ of transfection, the experimental medium was added to the cells followed by exposure to TNF- $\alpha(10 \mathrm{ng} / \mathrm{ml})$ in the absence or presence of GW9662 $(1 \mu \mathrm{M})$. The efficacy of transfection was obtained by examining the green fluorescence by microscopy (Nikon, Tokyo, Japan).

Intracellular ROS production assay. Confluent HUVECs in 6 -well plates were pretreated with EETs for $1 \mathrm{~h}$. Following removal of the EETs from the wells, the cells were incubated with $20 \mu \mathrm{M} \mathrm{HB}{ }_{2 \mathrm{~B}} \mathrm{DCF}-\mathrm{DA}$ for $30 \mathrm{~min}$ and then stimulated with TNF- $\alpha(10 \mathrm{ng} / \mathrm{ml})$ for $1 \mathrm{~h}$. The fluorescence intensity was measured at an excitation and emission wavelength of 485 and $530 \mathrm{~nm}$, respectively, using a fluorescence spectrophotometer or a fluorescence microscopy (Nikon). Values for each treatment group were recorded as the mean fluorescence intensity.

VSMCs Transwell assay. Transwsell 12-well plates were obtained from Costar Corp. (Cambridge, MA, USA). Monolayers of serum-starved adherent cells were trypsinized and cell suspensions were placed in serum-free medium in the upper well of a Transwell filter apparatus. The filter was suspended in a well of a 12-well plate and the lower reservoir was filled with the same medium (no cells) plus added TNF- $\alpha$. The cells were incubated under basal condition for $12 \mathrm{~h}$. The cells were stained with DAPI (Wuhan Boster Biological Technology) and cells found on the underside of the filter were counted by microscopy (Nikon).

Western blot analysis. HUVECs and macrophages were pretreated with exogenous EETs $(1 \mu \mathrm{M})$ and PPAR $\gamma$ inhibitor GW9662 for $1 \mathrm{~h}$, and then stimulated with or without TNF- $\alpha$ (10 ng/ml). Cultured HUVECs and macrophage were lysed in RIPA buffer containing a mixture of protease inhibitors, and the total protein concentration was determined by protein assay. Proteins $(50 \mu \mathrm{g})$ from cell lysates were electrophoresed by SDS-PAGE, proteins and nuclear extracts were then transferred to a PVDF membrane (Roche Diagnostics, Mannheim, Germany). The membrane was blocked with blocking buffer (1X TBS, $0.1 \%$ Tween-20, 5\% non-fat dry milk), and washed 
A

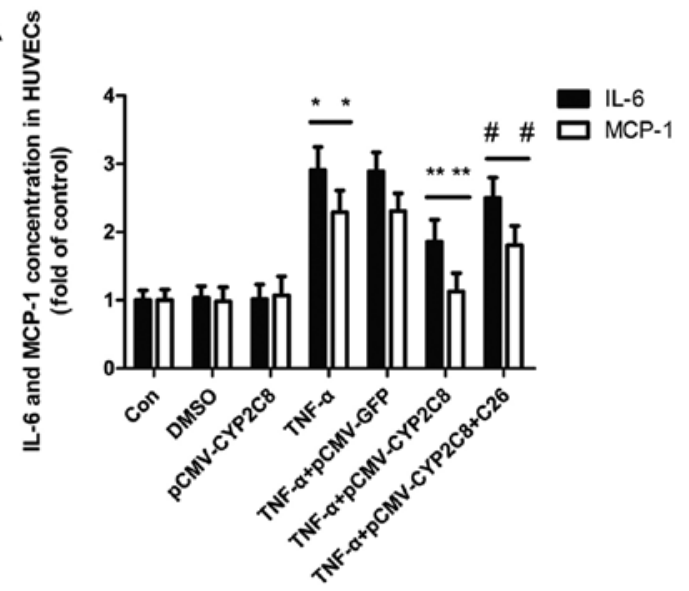

C

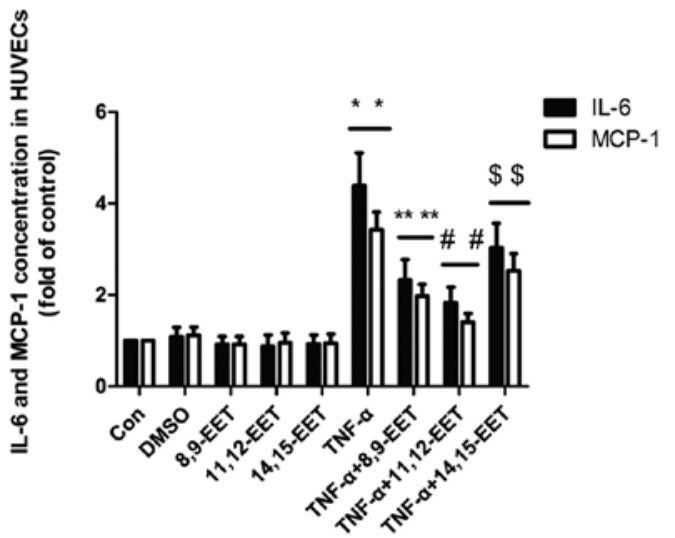

B

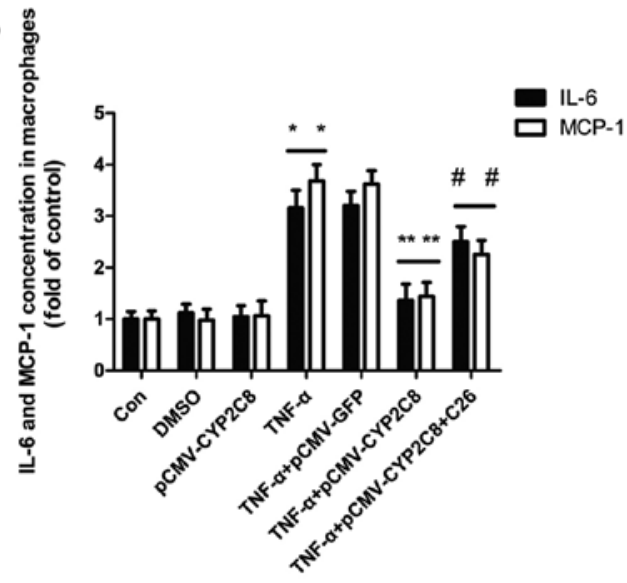

D

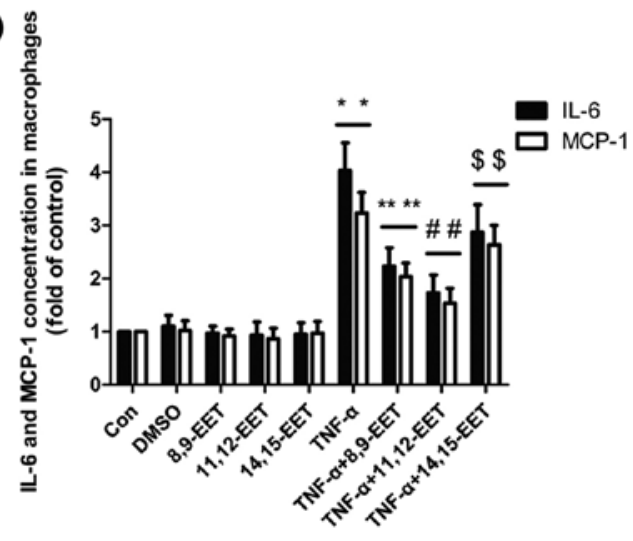

Figure 1. CYP2C8-derived EETs attenuated TNF- $\alpha$ induced inflammation by decreasing the levels of inflammatory factor MCP-1 and IL-6. (A) Primary cultures of HUVECs were transfected with CYP2C8 and administered with CYP2C8 inhibitor C26 for $60 \mathrm{~min}$ and stimulated with TNF- $\alpha$ (10 ng/ml) for $24 \mathrm{~h}$. $\left({ }^{*} \mathrm{P}<0.05\right.$ vs. control group; ${ }^{* *} \mathrm{P}<0.05$ vs. TNF- $\alpha$ treatment group; ${ }^{\#} \mathrm{P}<0.05$ vs. no inhibitor treatment group). (B) Macrophages were transfected as described in (A). ( $\mathrm{P}<0.05$ vs. control group; ${ }^{* *} \mathrm{P}<0.05$ vs. TNF- $\alpha$ treatment group; ${ }^{*} \mathrm{P}<0.05$ vs. no inhibitor treatment group). (C) Primary cultures of HUVECs were pretreated with exogenous 8,9-EET $(1 \mu \mathrm{M}), 11,12$-EET $(1 \mu \mathrm{M})$ and 14,15-EET $(1 \mu \mathrm{M})$, respectively, for 60 min and stimulated with TNF- $\alpha(10 \mathrm{ng} / \mathrm{ml})$ for $24 \mathrm{~h}$ $\left({ }^{*} \mathrm{P}<0.05\right.$ vs. control group; ${ }^{* *} \mathrm{P}<0.05,{ }^{\#} \mathrm{P}<0.05$ and ${ }^{\$} \mathrm{P}<0.05$ vs. TNF- $\alpha$ treatment group). (D) Macrophages were pre-treated with exogenous $8,9-\mathrm{EET}(1 \mu \mathrm{M})$, 11,12-EET $(1 \mu \mathrm{M})$ and 14,15-EET $(1 \mu \mathrm{M})$, respectively, for $60 \mathrm{~min}$ and stimulated with TNF- $\alpha(10 \mathrm{ng} / \mathrm{ml})$ for $24 \mathrm{~h}$. ( ${ }^{*} \mathrm{P}<0.05 \mathrm{vs}$. control group; ${ }^{* *} \mathrm{P}<0.05,{ }^{\#} \mathrm{P}<0.05$ and ${ }^{\$} \mathrm{P}<0.05$ vs. TNF- $\alpha$ treatment group). Data are the mean \pm SEM of results from at least five independent experiments, each performed in triplicate.

and incubated overnight at $4^{\circ} \mathrm{C}$ with anti-NF- $\mathrm{B}$ p-65 $(1: 1,000$ dilution), anti-IкB $\alpha$ (1:1,000 dilution), anti-eNOS (1:1,000 dilution), anti-gp-91 (1:1,000 dilution), anti- $\beta$-actin (1:1,000 dilution) or anti-lamin B-1 (1:1,000 dilution) primary antibodies. The membrane was subsequently washed with TBS-T $(10 \mathrm{mmol} / \mathrm{l}$ Tris- $\mathrm{HCl}, 150 \mathrm{mmol} / 1 \mathrm{NaCl}$, and $0.1 \%$ Tween-20) and incubated with horseradish peroxidase-conjugated secondary antibodies at $37^{\circ} \mathrm{C}$ for $1 \mathrm{~h}$. The immune complex was detected with an enhanced chemiluminescence system (Beyotime Institute of Biotechnology, Jiangsu, China), exposed to X-ray film, and analyzed using ImageJ 2 x software. $\beta$-actin and lamin B-1 were used as an internal control.

Measurement of MCP-1 and IL-6 level by enzyme-linked immunosorbent assay (ELISA). The level of MCP-1 and IL-6 in the supernatants was measured using a commercially available kit from Wuhan Boster Biological Technology according to the manufacturer's instructions. Optical densities were recorded on a universal microplate reader (Bio Tek Instruments, VT, Winooski, USA) at $450 \mathrm{~nm}$.

Statistical analysis. Data are presented as the mean \pm SEM. In vitro experiments were performed a total of 4-6 times, and each experiment was carried out in triplicate for each treatment group. Statistical comparisons among groups were performed by the Wilcoxon test, the Student's t-test or ANOVA as appropriate. In all cases, statistical significance was defined as $\mathrm{P}<0.05$.

\section{Results}

Transfection with CYP2C8 attenuated TNF- $\alpha$ induced inflammation by decreasing the levels of inflammatory factor $M C P-1$ and IL-6. The levels of inflammatory factors MCP-1 and IL-6 were examined in macrophages and HUVECs. pCMVCYP2C8 delivery led to an abundant CYP2C8 expression and increased EETs generation. ELISA analysis showed that transfection with CYP2C8 markedly suppressed the expression of inflammatory cytokines including interleukin (IL)-6 and MCP-1 induced by TNF- $\alpha$, which was reversed by CYP2C8 inhibitor C26 (Fig. 1A and B). As shown in Fig. 1C and D, 8,9-EET, 11,12-EET and 14,15-EET markedly reduced the IL- 6 and MCP-1 expression induced by TNF- $\alpha$ in HUVECs and macrophages, with 11,12-EET exerting the most significant effect. Therefore, we used 11,12-EET as the representative of EET in the subsequent experiments. 
A
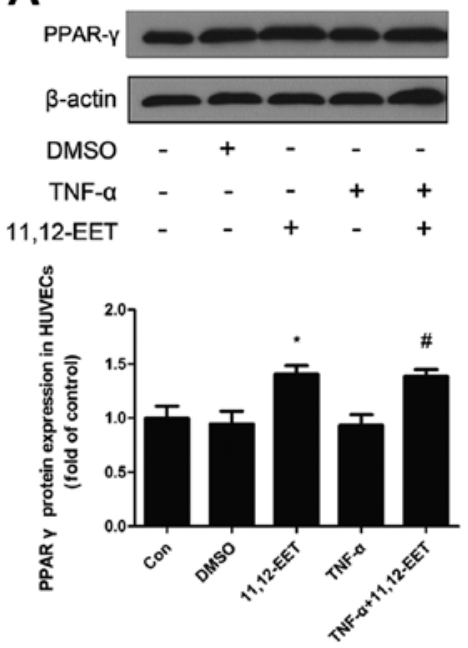

D
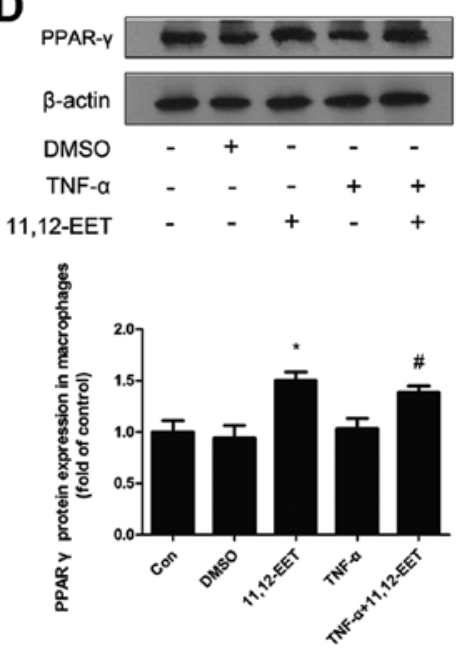

B
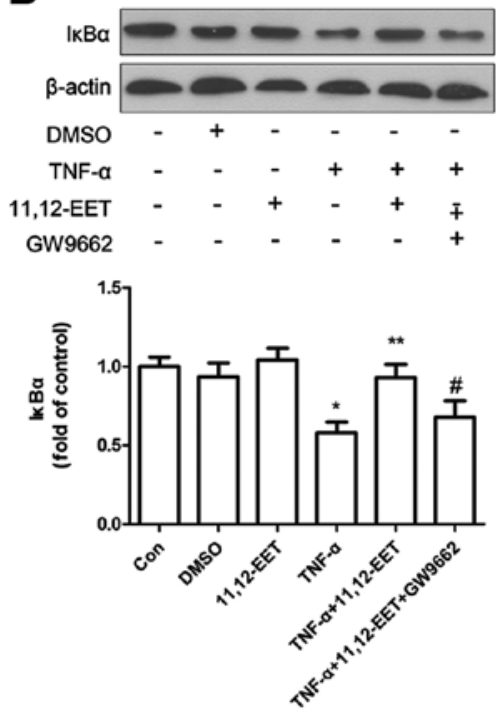

$\mathbf{E}$
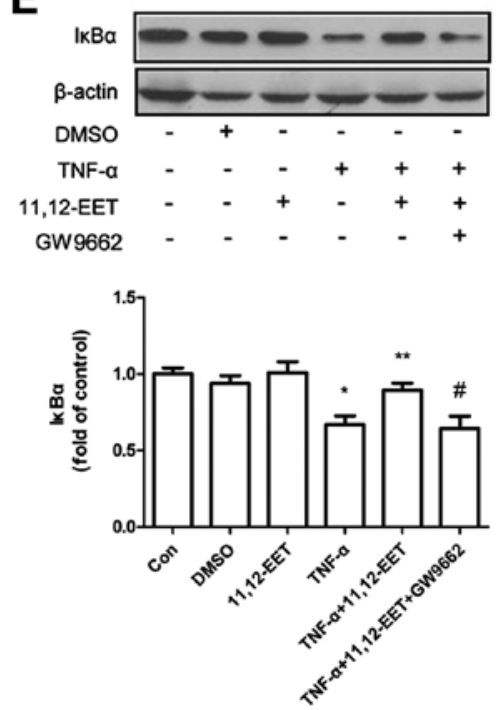
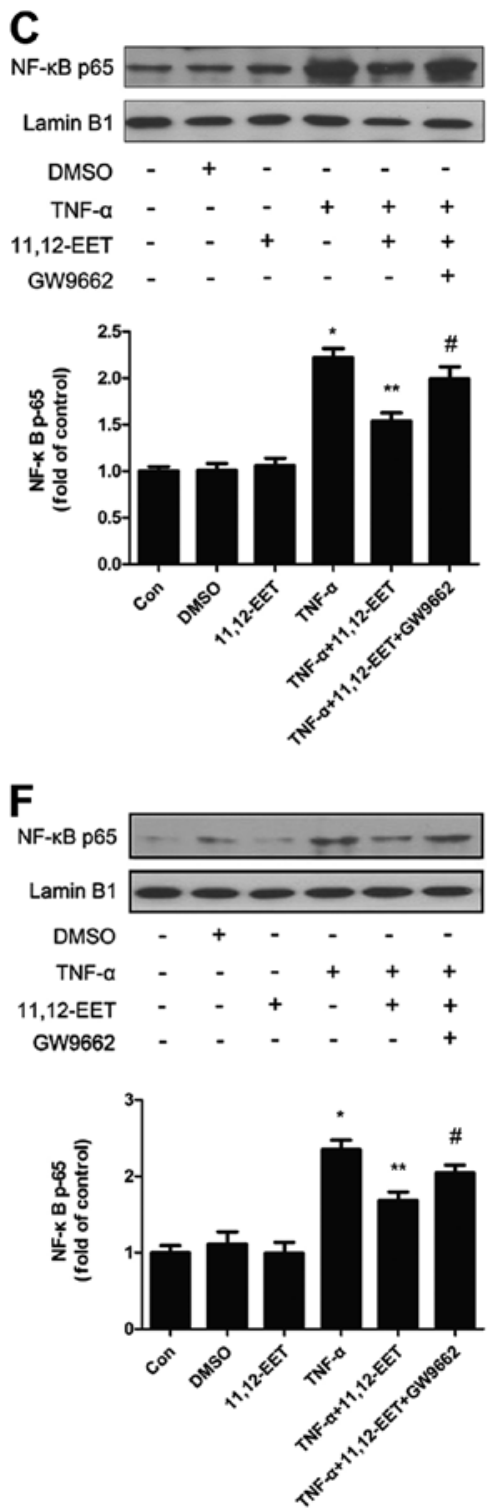

Figure 2. Exogenous CYP2C8-derived EETs inhibited TNF- $\alpha$ induced expression of NF- $\kappa$ B in HUVECs and macrophages. (A) PPAR $\gamma$ increased under the administration of 11,12 -EET in HUVECs ( $\mathrm{P}<0.05$ vs. control group; ${ }^{\prime} \mathrm{P}<0.05$ vs. TNF- $\alpha+\mathrm{EET}$ group). (B and C) Primary cultures of HUVECs were pretreated with EETs $(1 \mu \mathrm{M})$ and GW9662 $(1 \mu \mathrm{M})$ for $60 \mathrm{~min}$ and stimulated with TNF- $\alpha(10 \mathrm{ng} / \mathrm{ml})$ for $24 \mathrm{~h}$. ( ${ }^{*} \mathrm{P}<0.05 \mathrm{vs}$. control; ${ }^{* *} \mathrm{P}<0.05 \mathrm{vs}$. TNF- $\alpha$ treated control; ${ }^{\#} \mathrm{P}<0.05$ vs. TNF- $\alpha+E E T$ group). (D) PPAR $\gamma$ increased under the administration of 11,12 -EET in macrophages $\left({ }^{*} \mathrm{P}<0.05\right.$ vs. control group; ${ }^{\#} \mathrm{P}<0.05$ vs. TNF- $\alpha+E E T$ group). (E and F) Primary cultures of macrophages were pre-treated with EETs $(1 \mu \mathrm{M})$ and GW9662 (1 $\mu \mathrm{M})$ for 60 min and stimulated with TNF- $\alpha(10 \mathrm{ng} / \mathrm{ml})$ for $24 \mathrm{~h}$. ( $\mathrm{P}<0.05 \mathrm{vs}$. control; ${ }^{* * *} \mathrm{P}<0.05 \mathrm{vs}$. TNF- $\alpha$ treated control; ${ }^{*} \mathrm{P}<0.05$ vs. TNF- $\alpha+\mathrm{EET}$ group). Data are the mean \pm SEM of results from at least five independent experiments, each performed in triplicate.

CYP2C8-derived EETs inhibited TNF- $\alpha$ induced expression of $N F-\kappa B$ through PPAR in HUVECs and macrophages. To elucidate how CYP2C8 plays a role on anti-inflammation, it is necessary to examine the possible mechanism of CYP2C8-derived EET on anti-inflammation. Results of the western blot analysis revealed that 11,12-EET increased the protein expression of PPAR $\gamma$, which was the possible acceptor of EETs and associated with inflammation (24) (Fig. 2A and D), both in the basal and inflammatory condition. Therefore, we hypothesized that the overexpression of CYP2C8 in vitro to increase EETs may prevent the development of inflammation potentially through PPAR $\gamma$ activation. Moreover, we assessed the vital transcription factor $N F-\kappa B$ and the conclusion was consistent in HUVECs and macrophages. I $\mathrm{B} \alpha$ expression was decreased under the stimulation of TNF- $\alpha$, which could be reversed by 11,12-EET (Fig. 2B and E). The $\mathrm{NF}-\kappa \mathrm{B}$ subunit $\mathrm{p}-65$ expression was opposite to the effect of $\mathrm{I} \kappa \mathrm{B} \alpha$ (Fig. $2 \mathrm{C}$ and F). Notably, after adding PPAR $\gamma$-specific inhibitor GW9662, the beneficial effects caused by exogenous 11,12-EET were attenuated, indicating that 11,12-EET may be involved through the PPAR $\gamma$ pathway in blocking the activation of $\mathrm{NF}-\kappa \mathrm{B}$.

11,12-EET decreased TNF- $\alpha$ induced intracellular ROS production. Mounting evidence has indicated that the induction of ROS was necessary for the development of atherosclerosis and EETs possessed the ability of anti-atherosclerosis. To confirm the beneficial effects of 11,12-EET on atherosclerosis, intracellular ROS production induced by TNF- $\alpha$ in HUVECs were measured. The results showed that 11,12-EET decreased 
A
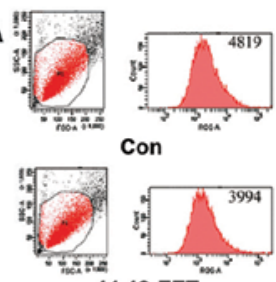

11,12-EET

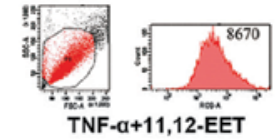

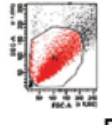

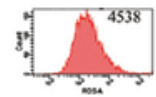

DMSO

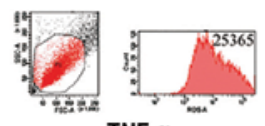

TNF- $\alpha$

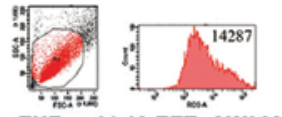

TNF- $\alpha+11,12-E E T+G W 962$
B
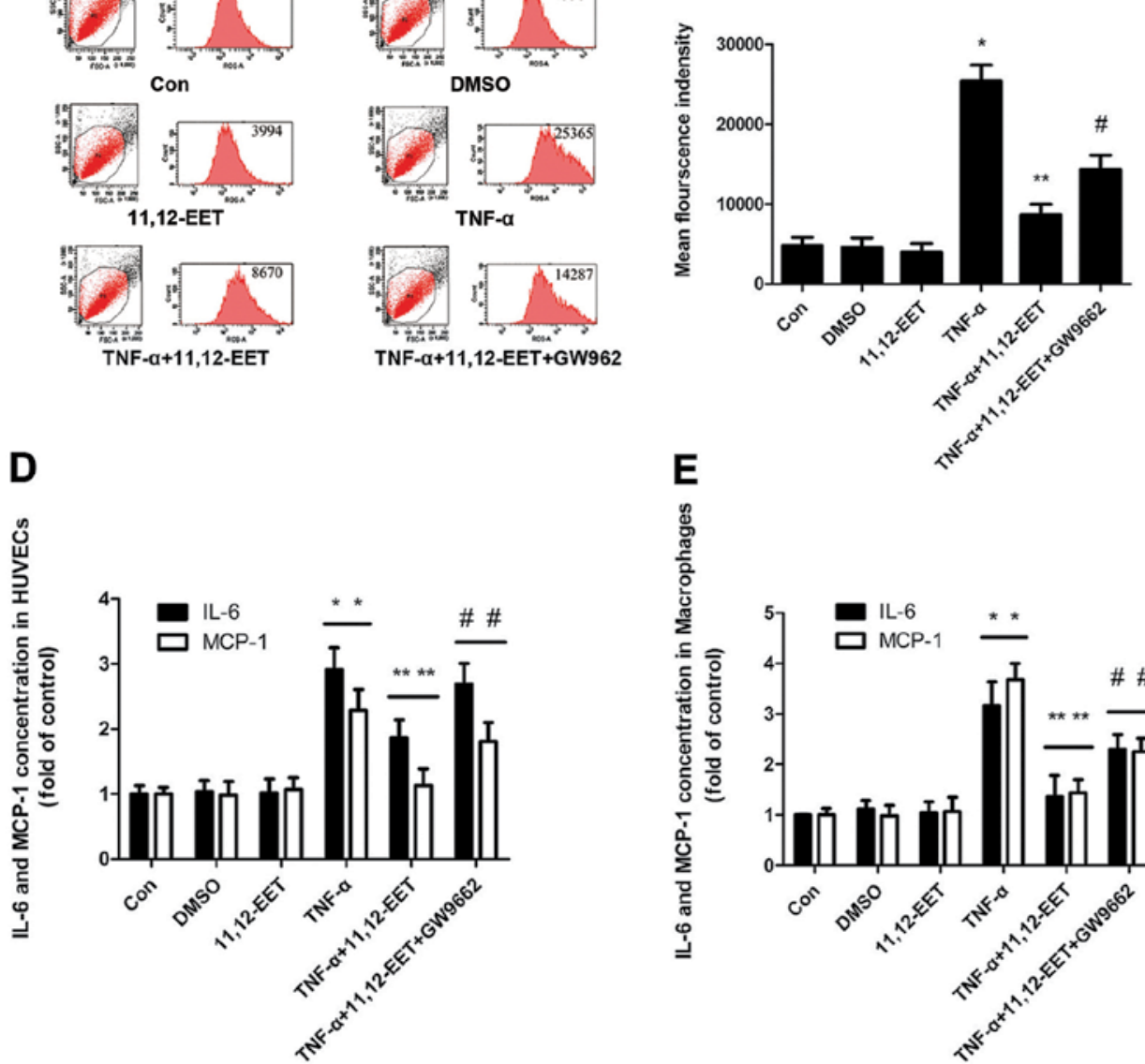

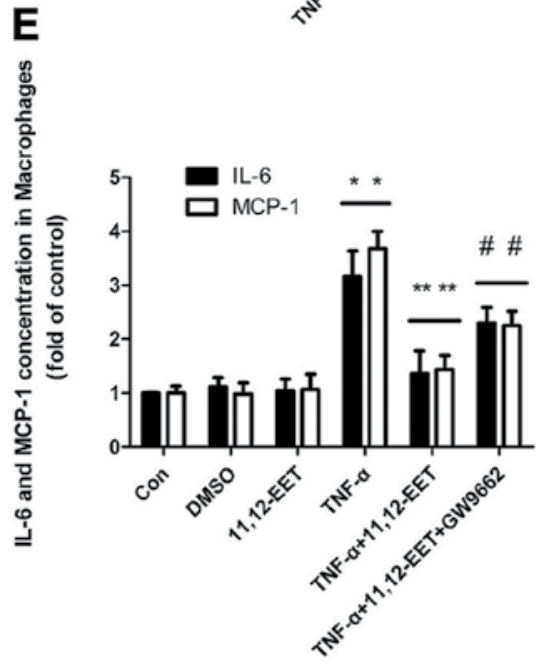

C
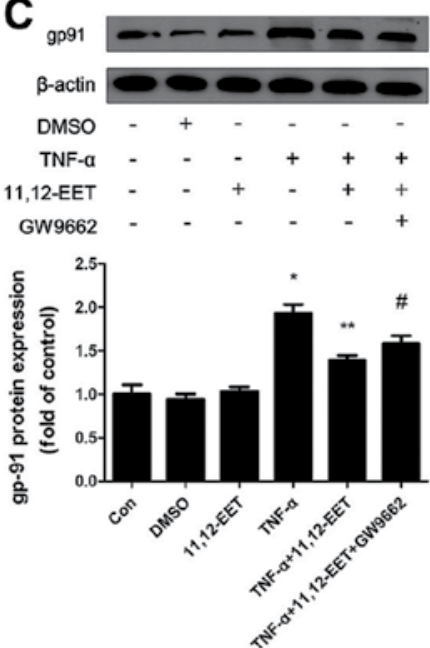

Figure 3. Exogenous CYP2C8-derived EETs decreases TNF- $\alpha$-induced ROS production. (A) Primary cultures of HUVECs were pre-treated with EETs (1 $\mu$ M) and GW9662 $(1 \mu \mathrm{M})$ for $60 \mathrm{~min}$ and stimulated with TNF- $\alpha(10 \mathrm{ng} / \mathrm{ml})$ for $24 \mathrm{~h}$. Cells were stained with HB ${ }_{2 \mathrm{~B}}$ DCF-DA. ROS production was measured by a fluorescence-activated cell sorter. (B) Quantification of the mean fluorescence intensity in different groups of cells. (C) Western blot analysis revealed that gp-91 was upregulated following stimulation with TNF- $\alpha$ and decreased under the influence of 11,12-EET. (D and E) Exogenous 11,12-EET decreased IL-6 and MCP-1 in HUVECs and macrophages, respectively. Values are the mean $\pm \mathrm{SEM}$ of five experiments. $\left({ }^{*} \mathrm{P}<0.05\right.$ vs. control; ${ }^{* *} \mathrm{P}<0.05$ vs. TNF- $\alpha$ treated control; ${ }^{\#} \mathrm{P}<0.05$ vs. TNF- $\alpha+$ EET group).

the ROS production induced by TNF- $\alpha$ and suppressed the TNF- $\alpha$-induced mean fluorescence intensity of the dye to a level that was comparable with that of the control. However, following the addition of the PPAR $\gamma$-specific inhibitor GW9662, the anti-oxidative effect caused by 11,12-EET was also attenuated (Fig. 3A and B). Results of the western blot analysis revealed that the ROS-associated NAD(P)H subunit gp-91 was increased almost 2-fold compared with the control when stimulated with TNF- $\alpha$. However, this effect disappeared following the addition of 11,12-EET (Fig. 3C). Therefore, 11,12-EET performed the coincident anti-inflammatory effect through the exogenous administration and $C Y P 2 C 8$ gene transfection. 11,12-EET pre-incubation reduced the expression of IL- 6 and MCP-1 induced by TNF- $\alpha$ in HUVECs and macrophages (Fig. 3D and E). Moreover, the PPAR $\gamma$-specific inhibitor GW9662 partially eliminated the beneficial effects of CYP2C8 transfection or the exogenous supply with 11,12-EET. $\mathrm{NF}-\kappa \mathrm{B}$ was one of the major transcription factors regulating the TNF- $\alpha$-induced expression of inflammatory biomarkers in HUVECs and macrophages, while ROS was crucial in inflammation. Thus, the CYP2C8/EET/PPAR $\gamma / \mathrm{ROS} / \mathrm{NF}-\kappa \mathrm{B}$ pathway may regulate the TNF- $\alpha$ induced inflammatory cytokine expression in HUVECs and macrophages.
CYP2C8-derived EETs improve endothelial function through the upregulation of eNOS. In addition, eNOS catalyzed the formation of NO characterized as an anti-atherosclerosis effect. To examine how CYP2C8-derived EETs affect the eNOS expression, CYP2C8 transfection was performed. pCMV-CYP2C8 transfection led to a substantial expression of CYP2C8 in HUVECs. Moreover, western blot analysis revealed a CYP2C8 protein overexpression in HUVECs (Fig. 4A and B) and eNOS was upregulated by CYP2C8 overexpression, which was decreased significantly under the stimulation of TNF- $\alpha$ (Fig. 4C). This effect suggested that CYP2C8 overexpression could increase the eNOS protein expression, which contributed to improving endothelial function and anti-atherosclerosis.

CYP2C8-derived EETs increased the migration of VSMCs. To assess the effect of CYP2C8-derived EETs on VSMC migration, we applied the Transwell migration model. pCMV-CYP2C8 transfection led to an abundant expression of CYP2C8 in VSMCs (Fig. 5A and B). The Transwell results showed that TNF- $\alpha$ increased the ability of the migration of VSMCs significantly. Additionally, EETs reversed the increased migration by TNF- $\alpha$. TNF- $\alpha+$ EET+GW9662 also exerted a similar effect as TNF- $\alpha$ on migration (Fig. 5 C and D). 
A

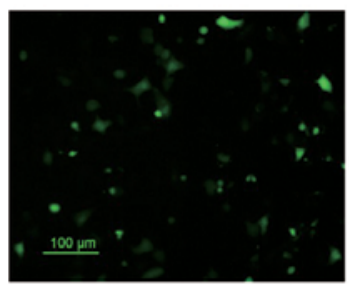

B

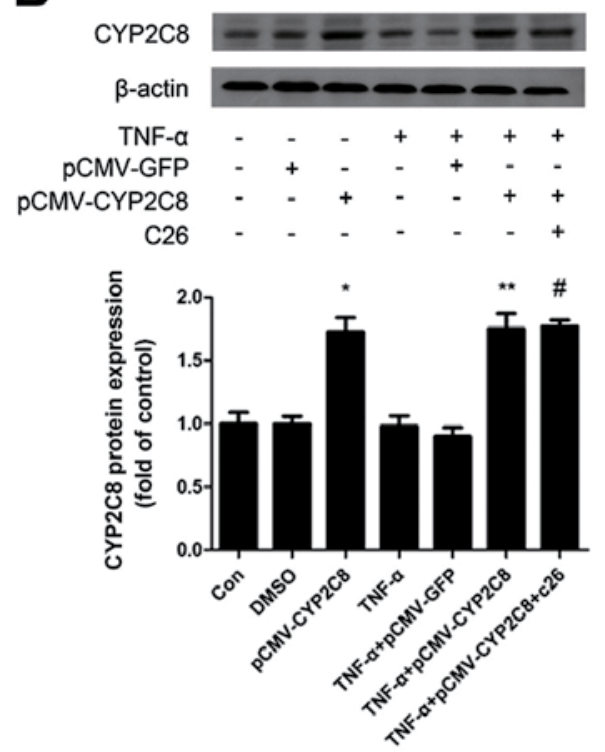

C

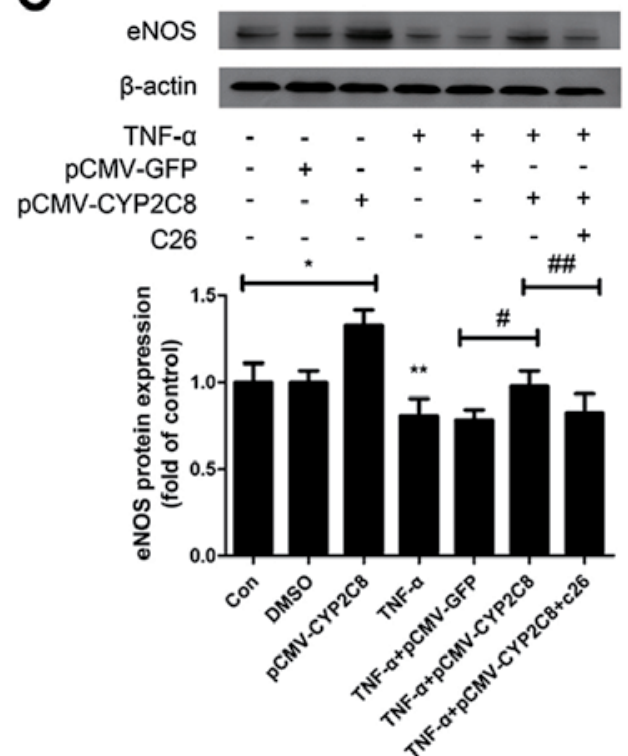

Figure 4. CYP2C8-derived EETs improve endothelial function through the upregulation of eNOS. (A) pCMV-CYP2C8 transfection led to a substantial expression of CYP2C8 in HUVECs. (B) Western blot analysis revealed the CYP2C8 protein expression. (C) The expression of eNOS in HUVECs. Data are the mean $\pm \mathrm{SEM}$ of results from at least five independent experiments, each performed in duplicate $\left({ }^{*} \mathrm{P}<0.05 \mathrm{vs}\right.$. control; ${ }^{* *} \mathrm{P}<0.05 \mathrm{vs}$. TNF- $\alpha$ treated control; ${ }^{\text {"}} \mathrm{P}<0.05$ vs. TNF- $\alpha+$ pCMV-CYP2C8 group).

These results indicated that CYP2C8-derived EETs possess an anti-TNF- $\alpha$ effect on cell migration and may play a role through the PPAR $\gamma$ pathways.

\section{Discussion}

The present study has demonstrated that CYP2C8-derived EETs significantly suppressed TNF- $\alpha$-induced intracellular ROS formation and the redox-sensitive NF- $\mathrm{NB}$ activation via the suppression of $\mathrm{I} \kappa \mathrm{B}$ degradation and phosphorylation. We investigated $C Y P 2 C 8$ gene-alleviated vascular inflammation through the CYP2C8/EET/PPAR $\gamma / \mathrm{ROS} / \mathrm{NF}-\kappa \mathrm{B}$ signaling pathway and improved endothelial function through the upregulation of eNOS and it may ameliorate the migration of VSMCs. These results have demonstrated that CYP2C8-derived EETs exerted antivascular inflammatory and anti-oxidative effects and it may be useful in the prevention and treatment of vascular inflammatory diseases.

Our previous study indicated that CYP2C8 exerted a protective effect on atherosclerosis induced by a western-type diet in $\mathrm{APOEKO}^{+/-} \mathrm{CYP} 2 \mathrm{C} 8 \mathrm{Tg}^{+/-}$and $\mathrm{CYP} 2 \mathrm{C} 8 \mathrm{Tg}^{+/-}$mice (25). The formation and area of atherosclerosis plaque was decreased significantly in teh aortic artery in the $C Y P 2 C 8$ gene overexpression group. To the best of our knowledge, the present study provided the first evidence that CYP2C8-derived EETs suppressed TNF- $\alpha$-induced inflammation through the suppression of $\mathrm{NF}-\kappa \mathrm{B}$ activation and ROS in HUVECs. Thus, we revealed that $\mathrm{CYP} 2 \mathrm{C} 8$-derived EETs prevented the early pathogenesis of atherosclerosis by modulating vascular inflammation and ROS.

The production of intercellular ROS induced by cytokines such as TNF- $\alpha$ has been suggested in the activation of NF- $\kappa \mathrm{B}$ and expression of inflammatory biomarkers (26-28). In the present study, TNF- $\alpha$ increased intercellular ROS production and we confirmed that CYP2C8-derived EETs decreased ROS generation in TNF- $\alpha$-stimulated HUVECs. Thus, the inhibition of ROS generation by CYP2C8-derived EETs may contribute to the inhibition $\mathrm{NF}-\kappa \mathrm{B}$ activation and expression of inflammatory biomarkers.

To identify the molecular mechanism by which CYP2C8derived EETs exerted its anti-inflammatory effect on TNF- $\alpha$-stimulated endothelial cells and macrophage, we examined the activation of $\mathrm{NF}-\kappa \mathrm{B}$, one of the major transcription factors regulating the TNF- $\alpha$-induced expression of inflammatory biomarkers in endothelial cells and macrophage $(29,30)$. NF- $\kappa \mathrm{B}$ is present in the cytosol as a heterodimer composed of $\mathrm{p} 50$ and $\mathrm{p} 65$ subunits bound to the inhibitor protein I $\mathrm{B}$ family in unstimulated cells. Following stimulation with cytokine, the I $\kappa \mathrm{B}$ proteins are phosphorylated and degraded, which allows $\mathrm{NF}-\kappa \mathrm{B}$ to translocate into the nucleus and initiates gene transcription (31). Our present results show that CYP2C8derived EETs significantly suppressed TNF- $\alpha$-induced I $\mathrm{B} \alpha$ degradation. We also observed that CYP2C8-derived EETs inhibited the TNF- $\alpha$-induced phosphorylation of $N F-\kappa B$ p65 at serine 536 and nuclear translocation of NF- $\kappa \mathrm{B}$ p65. Furthermore, the activation of $\mathrm{NF}-\kappa \mathrm{B}$ has been associated with the transcription factor PPAR $\gamma$ (peroxisome proliferator-activated receptor $\gamma$ ) (32-34). PPAR $\gamma$ is a ligand-activated nuclear receptor, binding with the PPAR response element of the target gene promoter, that is involved in the transcription of the related gene $(35,36)$. We also confirmed that CYP2C8derived EETs decreased the levels of inflammatory factors such as MCP-1 and IL-6 in HUVECs and macrophage. Thus, our results suggest that CYP2C8-derived EETs attenuated the TNF- $\alpha$-induced NF- $\kappa$ B activation that would be critical for the timely inhibition of inflammatory mediator expression.

Additionally, results of this study have demonstrated that CYP2C8-derived EETs improved endothelial function 


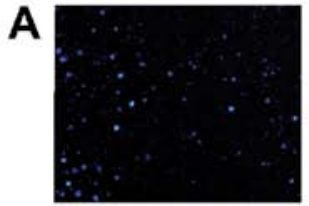

Control

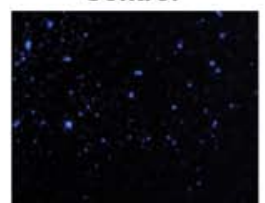

pCMV-CYP2C8

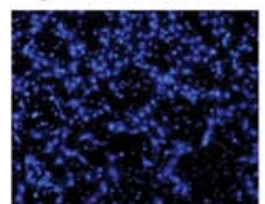

TNF- $\alpha+p C M V-G F P$

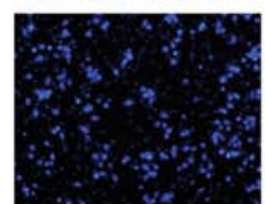

TNF- $\alpha+p C M V-C Y P 2 C 8+C 26$

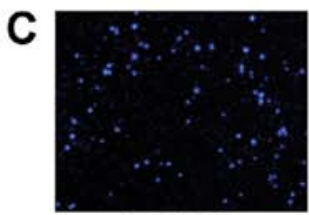

Control

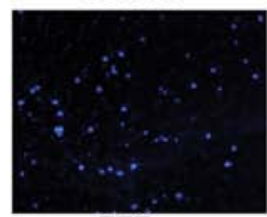

EET

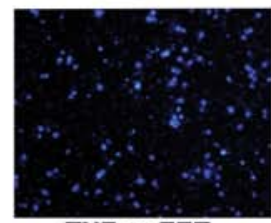

TNF- $\alpha+E E T$

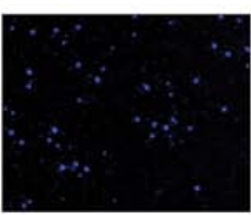

DMSO

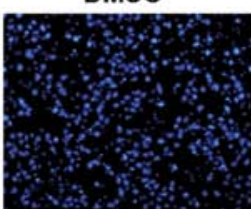

TNF- $\alpha$

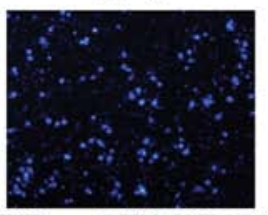

TNF- $\alpha+p C M V-C Y P 2 C 8$
B

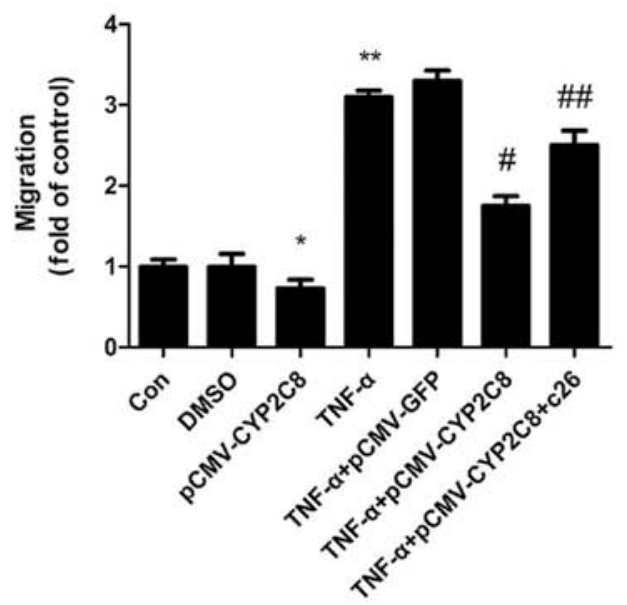

D

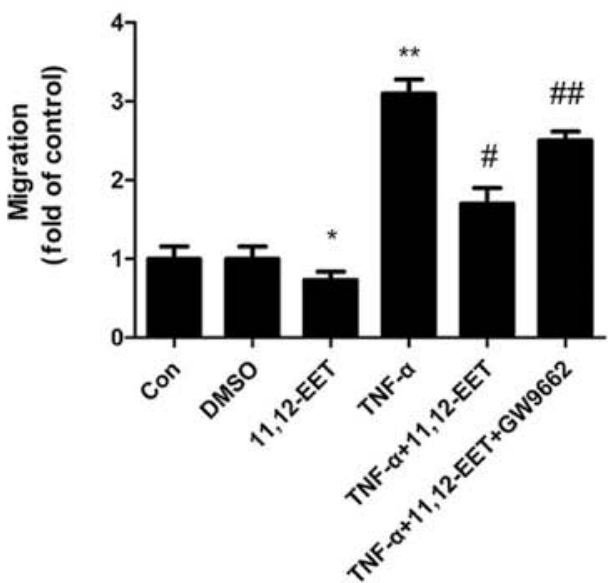

Figure 5. CYP2C8-derived EETs increased migration of VSMCs. (A and B) VSMCs were transfected with pCMV-CYP2C8 and pCMV-GFP and then stimulated with TNF- $\alpha$. The images show optical fields at different treatments (magnification, x200). (C and D) VSMCs were pre-incubated with EETs, GW9662 for $1 \mathrm{~h}$ and stimulated with or without TNF- $\alpha$ for $8 \mathrm{~h}$. The images show optical fields at different treatments (magnification, x200). Migration ability was quantified by the migration cell number at $8 \mathrm{~h}$. The nucleus of VSMCs were stained with DAPI. Data are shown as the mean \pm SEM ( $\mathrm{n}=5$ ). VSMCs were photographed and analysed by microscopy. The VSMCs were counted with Image-Pro Plus 5.0.2. Data are the mean \pm SEM of results from at least three independent experiments, each performed in duplicate. ( ${ }^{*} \mathrm{P}<0.01$ vs. control; ${ }^{* *} \mathrm{P}<0.01$ vs. TNF- $\alpha$ treated control; ${ }^{*} \mathrm{P}<0.001 \mathrm{vs}$. TNF- $\alpha+\mathrm{EET}$ group).

through the upregulation of eNOS. These results were consistent with those of a previous study (37). eNOS catalyzes the formation of NO, thus it may be characterized as exerting an anti-atherosclerotic effect.

Moreover, we confirm that CYP2C8-derived EETs are involved in the migration of VSMCs. In our experiments TNF- $\alpha$ increased the migration of VSMCs significantly and CYP2C8-derived EETs decreased their migration. As previous studies have demonstrated that the migration of VSMCs was associated with the formation of atherosclerosis (38-41), the decrease of the migration of VSMCs by CYP2C8-derived EETs may contribute to the improvement of atherosclerosis.

In conclusion, vascular inflammation induced by cytokine occurs early in the development of atherosclerosis and leads to endothelial dysfunction. Thus, these data have provided insight on the actions of CYP2C8-derived EETs and its potential benefits on preventing inflammatory diseases such as atherosclerosis. 


\section{Acknowledgements}

The present study was supported by the National Nature Science Foundation of China (no. 81170259) and the Key Project of Health Ministration.

\section{References}

1. Ross R: Atherosclerosis - an inflammatory disease. N Engl J Med 340: 115-126, 1999.

2. Guzik TJ, Korbut R and Adamek-Guzik T: Nitric oxide and superoxide in inflammation and immune regulation. J Physiol Pharmacol 54: 469-487, 2003.

3. Cai H: Hydrogen peroxide regulation of endothelial function: origins, mechanisms, and consequences. Cardiovasc Res 68 26-36, 2005.

4. Madamanchi NR, Hakim ZS and Runge MS: Oxidative stress in atherogenesis and arterial thrombosisthe disconnect between cellular studies and clinical outcomes. J Thromb Haemost 3: 254-267, 2005

5. Forstermann U: Oxidative stress in vascular disease: causes, defense mechanisms and potential therapies. Nat Clin Pract Cardiovasc Med 5: 338-349, 2008.

6. Park JG and Oh GT: The role of peroxidases in the pathogenesis of atherosclerosis. BMB Rep 44: 497-505, 2011.

7. Cominacini L, Pasini AF, Garbin U, et al: Oxidized low density lipoprotein (ox-LDL) binding to ox-LDL receptor-1 in endothelial cells induces the activation of NF- $\kappa \mathrm{B}$ through an increased production of intracellular reactive oxygen species. J Biol Chem 275: 12633-12638, 2000.

8. Miller YI, Viriyakosol S, Binder CJ, Feramisco JR, Kirkland TN and Witztum JL: Minimally modified LDL binds to CD14, induces macrophage spreading via TLR4/MD-2, and inhibits phagocytosis of apoptotic cells. J Biol Chem 278: 1561-1568, 2003.

9. Miller YI, Viriyakosol S, Worrall DS, Boullier A, Butler S and Witztum JL: Toll-like receptor 4-dependent and -independent cytokine secretion induced by minimally oxidized low-density lipoprotein in macrophages. Arterioscler Thromb Vasc Biol 25 1213-1219, 2005.

10. Bae YS, Lee JH, Choi SH, et al: Macrophages generate reactive oxygen species in response to minimally oxidized low-density lipoprotein: toll-like receptor 4- and spleen tyrosine kinasedependent activation of NADPH oxidase 2. Circ Res 104: 210-218, 2009.

11. Forman HJ and Torres M: Reactive oxygen species and cell signaling: respiratory burst in macrophage signaling. Am J Respir Crit Care Med 166: S4-S8, 2002.

12. Taniyama Y and Griendling KK: Reactive oxygen species in the vasculature: molecular and cellular mechanisms. Hypertension 42: 1075-1081, 2003.

13. De Keulenaer GW, Ushio-Fukai M, Yin Q, et al: Convergence of redox-sensitive and mitogen-activated protein kinase signaling pathways in tumor necrosis factor- $\alpha$-mediated monocyte chemoattractant protein-1 induction in vascular smooth muscle cells. Arterioscler Thromb Vasc Biol 20: 385-391, 2000.

14. Hulsmans $M$ and Holvoet P: The vicious circle between oxidative stress and inflammation in atherosclerosis. J Cell Mol Med 14: 70-78, 2010.

15. Sury MD, Frese-Schaper M, Muhlemann MK, et al: Evidence that $\mathrm{N}$-acetylcysteine inhibits TNF- $\alpha$-induced cerebrovascular endothelin-1 upregulation via inhibition of mitogen- and stressactivated protein kinase. Free Radic Biol Med 41: 1372-1383, 2006.

16. Yang WS, Lee JM, Han NJ, Kim YJ, Chang JW and Park SK: Mycophenolic acid attenuates tumor necrosis factor- $\alpha$-induced endothelin-1 production in human aortic endothelial cells. Atherosclerosis 211: 48-54, 2010.

17. Node K, Huo Y, Ruan X, et al: Anti-inflammatory properties of cytochrome P450 epoxygenase-derived eicosanoids. Science 285: 1276-1279, 1999.

18. Fisslthaler B, Popp R, Kiss L, et al: Cytochrome P450 2C is an EDHF synthase in coronary arteries. Nature 401: 493-497, 1999.

19. Wu S, Chen W, Murphy E, et al: Molecular cloning, expression, and functional significance of a cytochrome P450 highly expressed in rat heart myocytes. J Biol Chem 272: 12551-12559, 1997.
20. Zeldin DC, Foley J, Boyle JE, et al: Predominant expression of an arachidonate epoxygenase in islets of Langerhans cells in human and rat pancreas. Endocrinology 138: 1338-1346, 1997.

21. Michaelis UR, Fisslthaler B, Medhora M, Harder D, Fleming I and Busse R: Cytochrome P450 2C9-derived epoxyeicosatrienoic acids induce angiogenesis via cross-talk with the epidermal growth factor receptor (EGFR). FASEB J 17: 770-772, 2003.

22. Sun J, Sui X, Bradbury JA, Zeldin DC, Conte MS and Liao JK: Inhibition of vascular smooth muscle cell migration by cytochrome p450 epoxygenase-derived eicosanoids. Circ Res 90: 1020-1027, 2002.

23. Liu L, Chen C, Gong W, et al: Epoxyeicosatrienoic acids attenuate reactive oxygen species level, mitochondrial dysfunction, caspase activation, and apoptosis in carcinoma cells treated with arsenic trioxide. J Pharmacol Exp Ther 339: 451-463, 2011.

24. Wray J and Bishop-Bailey D: Epoxygenases and peroxisome proliferator-activated receptors in mammalian vascular biology. Exp Physiol 93: 148-154, 2008.

25. Wu J, Chen C, Zeng HS and Wang DW: The protective effects of cytochrome $\mathrm{P} 450$ gene on atherosclerosis induced by high fat diet in different week old mice. Mol Cardiol Chin 11: 37-41, 2011.

26. Sun J, Huang SH, Zhu YC, et al: Anti-oxidative stress effects of Herba leonuri on ischemic rat hearts. Life Sci 76: 3043-3056, 2005.

27. Simoncini T, Maffei S, Basta G, et al: Estrogens and glucocorticoids inhibit endothelial vascular cell adhesion molecule-1 expression by different transcriptional mechanisms. Circ Res 87: 19-25, 2000.

28. Liu X, Pan L, Gong Q and Zhu Y: Leonurine (SCM-198) improves cardiac recovery in rat during chronic infarction. Eur J Pharmacol 649: 236-241, 2010.

29. Wilson SH, Best PJ, Edwards WD, et al: Nuclear factor- $\kappa \mathrm{B}$ immunoreactivity is present in human coronary plaque and enhanced in patients with unstable angina pectoris. Atherosclerosis 160: 147-153, 2002.

30. Collins T and Cybulsky MI: NF- $\kappa$ B: pivotal mediator or innocent bystander in atherogenesis? J Clin Invest 107: 255-264, 2001.

31. Brasier AR: The nuclear factor- $\kappa \mathrm{B}$-interleukin-6 signalling pathway mediating vascular inflammation. Cardiovasc Res 86: 211-218, 2010.

32. Marx N, Duez H, Fruchart JC and Staels B: Peroxisome proliferator-activated receptors and atherogenesis: regulators of gene expression in vascular cells. Circ Res 94: 1168-1178, 2004.

33. Ricote M, Li AC, Willson TM, Kelly CJ and Glass CK: The peroxisome proliferator-activated receptor- $\gamma$ is a negative regulator of macrophage activation. Nature 391: 79-82, 1998.

34. Cipollone F, Fazia M, Iezzi A, et al: Balance between PGD synthase and PGE synthase is a major determinant of atherosclerotic plaque instability in humans. Arterioscler Thromb Vasc Biol 24: 1259-1265, 2004.

35. Dehmer T, Heneka MT, Sastre M, Dichgans J and Schulz JB: Protection by pioglitazone in the MPTP model of Parkinson's disease correlates with I $\mathrm{KB} \alpha$ induction and block of NF $\kappa \mathrm{B}$ and iNOS activation. J Neurochem 88: 494-501, 2004.

36. Castrillo A and Tontonoz P: PPARs in atherosclerosis: the clot thickens. J Clin Invest 114: 1538-1540, 2004.

37. Wang H, Lin L, Jiang J, et al: Up-regulation of endothelial nitricoxide synthase by endothelium-derived hyperpolarizing factor involves mitogen-activated protein kinase and protein kinase C signaling pathways. J Pharmacol Exp Ther 307: 753-764, 2003 .

38. Lee PC, Ho IC and Lee TC: Oxidative stress mediates sodium arsenite-induced expression of heme oxygenase-1, monocyte chemoattractant protein-1, and interleukin-6 in vascular smooth muscle cells. Toxicol Sci 85: 541-550, 2005.

39. Zhang T, Zhang X, Yu W, et al: Effects of chemokine-like factor 1 on vascular smooth muscle cell migration and proliferation in vascular inflammation. Atherosclerosis 226: 49-57, 2013.

40. Caglayan E, Romeo GR, Kappert K, et al: Profilin-1 is expressed in human atherosclerotic plaques and induces atherogenic effects on vascular smooth muscle cells. PLoS One 5: e13608, 2010.

41. Nakagawa M, Ohno T, Maruyama R, et al: Sesquiterpene lactone suppresses vascular smooth muscle cell proliferation and migration via inhibition of cell cycle progression. Biol Pharm Bull 30: 1754-1757, 2007. 